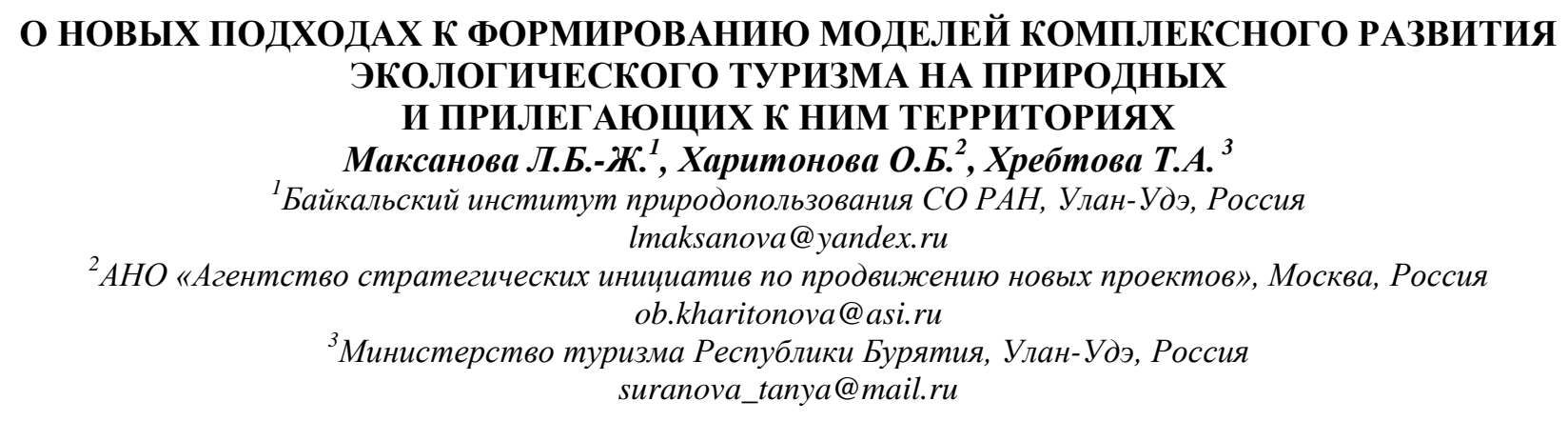

\title{
ON THE NEW APPROACHES IN THE FORMATION OF MODELS FOR THE INTEGRA TED DEVELOPMENT OF ECOLOGICAL TOURISM IN NATURAL AREAS AND THEIR SURROUNDINGS
}

\author{
Maksanova L.B.-Zh. ${ }^{1}$, Kharitonova O.B. ${ }^{2}$, Khrebtova T.A. ${ }^{3}$ \\ ${ }^{1}$ Baikal Institute of Nature Management SB RAS, Ulan-Ude, Russia \\ ${ }^{2} A N O$ "Agency for Strategic Initiatives for the Promotion of New Projects", Moscow, Russia \\ ${ }^{3}$ Ministry of Tourism of the Republic of Buryatia, Ulan-Ude, Russia
}

В статье рассматриваются новые подходы к формированию моделей комплексного развития экологического туризма на природных и прилагающих к ним территориях на основе изучения методологии и практики организации Всероссийского конкурса по выявлению пилотных территорий для создания туристско-рекреационных кластеров.

Ключевые слова: особо охраняемые природные территории, экологический туризм, Всероссийский конкурс, туристско-рекреационный кластер.

The article discusses new approaches to the formation of models for the integrated development of ecological tourism in protected and adjacent territories on the basis of studying the methodology and practice of organizing an All-Russian competition to identify pilot territories for creating tourist and recreational clusters.

Keywords: protected areas, ecological tourism, All-Russian competition, tourist and recreational cluster.

Особо охраняемые природные территории во всем мире вносят значительный вклад в охрану природы и являются основой для развития экотуризма. Многие страны, опираясь на международные рекомендации по устойчивому развитию экотуризма, и, исходя из собственных традиций, государственной политики, накопленного опыта и особенностей охраняемых территорий, используют разнообразный набор концепций, моделей и инструментов развития экотуризма на ООПТ [1-3].

Преимущества и характеристики экотуризма заключаются в том, что он стимулирует и удовлетворяет желание общаться с природой, предотвращает негативное воздействие на природу и культуру и побуждает участников туристской деятельности содействовать сохранению окружающей среды, экологическому просвещению, соблюдению интересов местных жителей и социальноэкономическому развитию территорий [4-5].

Российская Федерация располагает колоссальным потенциалом для развития экологического туризма [6-8]. Катализатором реализации национальной повестки по комплексному развитию экологического туризма стал впервые прошедший в 2020 г. Всероссийский конкурс по выявлению пилотных территорий для создания туристско-рекреационных кластеров (далее - Конкурс). Учитывая высокую значимость и роль нестандартного механизма выбора природных территорий для комплексного развития экологического туризма в работе рассматриваются методологические подходы и опыт организации данного Конкурса.

Конкурс организован Автономной некоммерческой организацией «Агентство стратегических инициатив по продвижению новых проектов» (далее - АСИ) при поддержке Минприроды России, Ростуризма, Минэкономразвития России и Министерства по развитию Дальнего Востока. Цели Кон- 
курса фокусировались на формировании прозрачного механизма выбора пилотных территорий для комплексного развития экологического туризма и формировании комплексных планов развития ТРК в увязке с развитием ООПТ и прилегающих территорий.

Практически все конкурсные процедуры осуществлялись на основе уникальной краудсорсинговой методики с использованием онлайн- и офлайн-сервисов, что демонстрирует новые, нестандартные инструменты для выявления лучших экотуристских проектов и объединения различных целевых сообществ, заинтересованных в развитии экотуризма на природных и прилегающих к ним территориях. Специфической особенностью Конкурса является формирование междисциплинарных региональных команд, ядром которых являются дирекции ООПТ. В составе команд, получивших поддержку глав субъектов Российской Федерации, представители региональных и муниципальных органов власти, предприниматели, экологи, ученые, преподаватели, архитекторы, дизайнеры, фермеры и др. Наибольшее количество участников в междисциплинарной команде представила Республика Бурятия (более 100 человек).

Конкурс включает два этапа: отборочный и акселерационный (рис. 1). При этом акселерация как цикл обучающих, методических, консультационных мероприятий сопровождает весь конкурс.

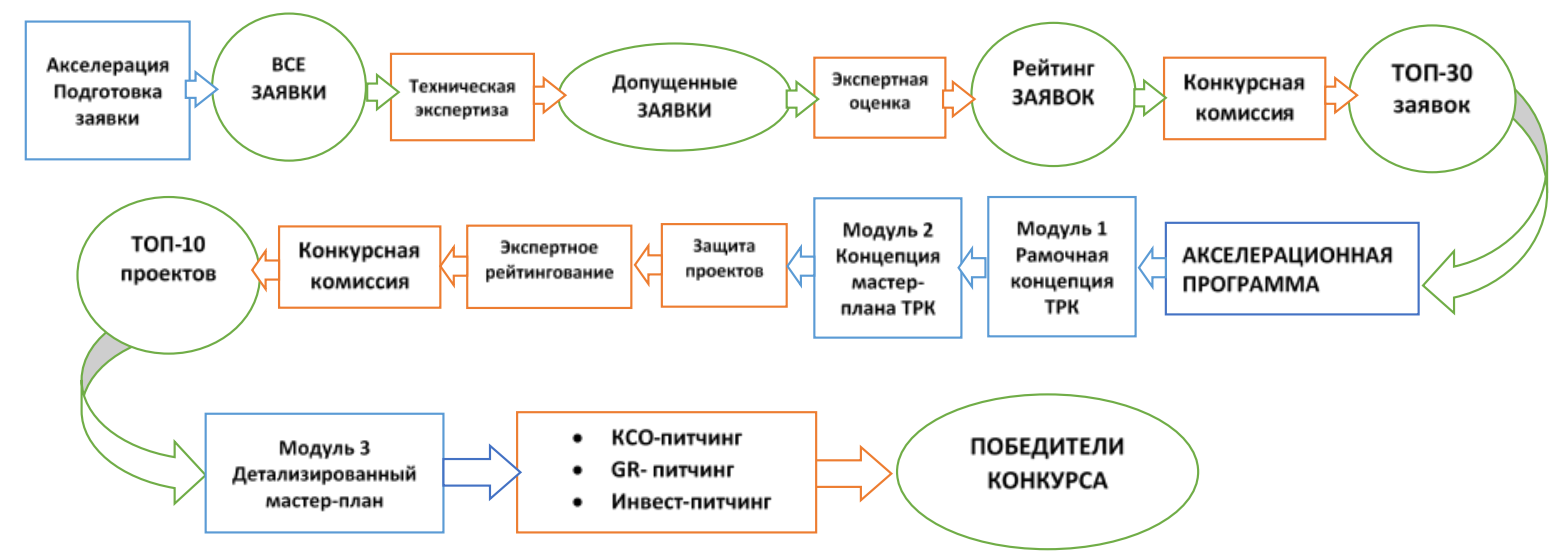

Рис. 1. Общая схема проведения Конкурса

Источник: составлено по [9]

Первый отборочный этап. Согласно Положению о конкурсе, его участниками в 2020 году стали ООПТ федерального и регионального значения. Всего на конкурс подали заявки 115 команд из 68 субъектов РФ и 8 федеральных округов (табл. 1).

Таблица 1

Общие сведения о региональных заявках, представленных на Всероссийский конкурс в 2020 г.

\begin{tabular}{|l|c|c|c|}
\hline \multicolumn{1}{|c|}{ Показатель } & $\begin{array}{c}\text { Зарегистрировано для уча- } \\
\text { стия в конкурсе }\end{array}$ & $\begin{array}{c}\text { Представлено на } \\
\text { конкурс }\end{array}$ & Доля, \% \\
\hline Количество заявок & 219 & 115 & $52 \%$ \\
\hline Количество субъектов РФ & 81 & 68 & $84 \%$ \\
\hline Площадь территорий, га & 112 & 58 & $52 \%$ \\
\hline Участники команд, чел. & 1075 & 926 & $86 \%$ \\
\hline Количество ООПТ, в рамках проектов, ед. & 523 & 231 & $44 \%$ \\
\hline
\end{tabular}

Источник: составлено по данным [9].

Особенностью Конкурса является возможность подготовки неограниченного количества заявок от региона.

Общее количество природоохранных территорий в рамках конкурсных заявок составляет 231 ООПТ, в том числе 63 ООПТ федерального и 168 - регионального значения.

Все поданные на конкурс заявки проходят техническую экспертизу с целью проверки комплектности представленных документов. Проверенные заявки направляются членам экспертной группы Конкурса для оценки по следующим критериям: 
- наличие на территории уникальных объектов показа международного, всероссийского или межрегионального уровней;

- принципиальное наличие привлекательности территории для инвестора при реализации комплексных решений по развитию экологического туризма и перспективный социально-экономический эффект от реализации проекта;

- оригинальность и обоснованность ключевой идеи с учетом итогов SWOT-анализа;

- сбалансированность и опыт команды [9].

По результатам экспертной оценки составлялся рейтинг региональных заявок, согласно которому оператор Конкурса представлял на рассмотрение конкурсной комиссии квалификационный анализ заявок с предложением тридцати лучших региональных проектов или Топ-30 финалистов отборочного этапа. В 2020 г. во второй этап (этап акселерации) прошли 36 проектов из 32 субъектов РФ, которые охватывают 97 ООПТ, из которых 33 - федерального и 64 - регионального значения.

На втором этапе отобранные 36 региональных команд принимали участие в акселерационной программе, которая включает цикл обучающих мероприятий и консультаций с экспертами по разработке рамочных концепций ТРК, по их архитектурно-планировочному решению, активизации предпринимательской и инвестиционный деятельности, созданию конкурентоспособного продукта, его продвижению.

Акселерационная программа состоит из подготовительной части и трех обучающих модулей. Первый и второй модули проходят все команды ТОП-36. Далее с целью выявления не менее 10 пилотных территорий с лучшими решениями, разработанными в рамках акселерационной программы, проводилась оценка региональных проектов по балльной системе с использованием следующих критериев:

- обоснованность модели функционирования территории (ООПТ и прилегающая к ним территория) с целью развития экологического туризма;

- качество функционально-планировочных решений территории;

- качество архитектурных, стилистических и функциональных предложений в отношении объектов туристической инфраструктуры;

- степень и разнообразие форм участия целевых аудиторий при подготовке проекта, социокультурное программирование территории;

- привлекательность предлагаемых решений для инвестора и потенциал привлечения внебюджетных источников;

- эффективность финансово-экономической модели развития;

- оценка социально-экономической эффективности реализации проекта [9].

Именно для этих пилотных территорий становится доступным третий модуль акселерации, в рамках которого ведется подготовка инвестиционных предложений, участие в КСО-питчинге (демонстрация программ корпоративной социальной ответственности), GR-питчинге (презентации перед профильными министерствами и ведомствами), инвест-питчинге (презентации инвестиционных проектов) и представление туристскому сообществу проектов ТРК.

К проведению обучающих программ были привлечены известные эксперты в области заповедного дела, проектирования природных территорий, организации туристского бизнеса, маркетинга и продвижения. За каждой командой был закреплен наставник (ментор), в функции которого входит организационно-методическое содействие в разработке и корректировке проекта создания ТРК. Учитывая многоаспектность рассматриваемых тем и профессиональный уровень привлеченных экспертов, можно утверждать, что акселерация позволила обеспечить одномоментное повышение компетенций 1000 человек, которые будут развивать проекты в сфере экотуризма вне зависимости от результатов конкурса. По итогам акселерационной программы были определены 17 победителей Конкурса, включая (а) ТОП10 пилотных территорий; (б) 6 территорий перспективного развития; (в) победителя народного голосования.

Невозможно не отметить еще одну специфическую особенность Конкурса - его высокое просветительское значение. На протяжении всех конкурсных процедур особое внимание уделялось проблемным вопросам сопряжения природоохранной и рекреационной функций ООПТ, социально- 
экономического развития территорий, формирования культуры отдыха и ответственного предпринимательства, иным актуальным вопросам создания и продвижения экотуристских продуктов и услуг ООПТ с использованием современных цифровых инструментов. Количество просмотров сайта Конкурса превысило 1,2 млн чел., а количество уникальных пользователей - 300 тыс. чел., без использования рекламных бюджетов на продвижение страницы.

Выполненный анализ материалов и результатов Конкурса демонстрирует активный интерес регионов в развитии туризма, опираясь на новые экотуристские возможности ООПТ, а также объединение различных сообществ в одну команду. Использование новых нестандартных подходов в виде акселерационной программы наряду с соревновательной составляющей конкурса является оригинальной и эффективной формой одномоментного повышения компетенций региональных команд и внедрения современного подхода к организации экотуризма на ООПТ.

Суммируя, следует отметить, что проведение Конкурса позволило: а) получить пространственный срез экотуристских инициатив и моделей; б) повысить качество и уровень подготовки региональных проектов; в) стимулировать мотивацию и объединить усилия стейкходеров к комплексному развитию туристских территорий и повышению ответственности за сохранение природы; г) усилить просветительское значение природоохранной политики.

В тоже время Конкурс показал, что несмотря на активизацию интереса к теме экотуризма, приоритеты его развития в регионах РФ формулируются по-разному. Эксперты указывают на необходимость формирования единого содержательного толкования термина «экотуризм» для потенциальных организаторов услуг и продуктов в этом сегменте туристского рынка. Более того, в ходе конкурса стало возможным распознать возникающие новые вызовы, которые требуют изучения и оценки их воздействия, формирования упреждающих мер, обновления стратегических и программных документов и др. Большим вызовом является сверхтуризм (overtourism), который способен обострить проблему превышения предельных допустимых нагрузок на ООПТ в процессе активной рекламной кампании. Еще одним вызовом является «агрессивная» коммерциализация ООПТ. Не все предложения о туристских продуктах и услугах, а также перечень объектов инфраструктуры, необходимых для оказания услуг на ООПТ и прилегающих территориях, были сформированы как совместимые с целями сохранения природы. Во многих проектах были представлены «горнолыжные курорты мирового уровня» и иные «дорогие» объекты инфраструктуры, не дающие проектам конкурентных преимуществ именно экологического туризма. Поэтому инфраструктурный «ажиотаж» должен сопровождаться разделением зон ответственности государства и бизнеса по эксплуатации природных территорий. Для правильного инфраструктурного обустройства природных объектов, решения вопросов безопасности людей, организации сервиса необходимо четко разграничить выявление отдельных видов рекреационных занятий и туристской деятельности, допустимых на охраняемых территориях. Весомым вызовом является низкий уровень компетенций у органов власти и инвесторов для работы с проектами на ООПТ. Изучение состава и компетенций команд, условий и результатов их деятельности демонстрирует нехватку специалистов различных компетенций и опыта взаимодействия с ООПТ, что существенно ограничивало их возможности качественной подготовки конкурсных документов. Несомненный вызов - это ущемление прав и интересов местных жителей. Анализ показал, что очень слабо проработаны вопросы, связанные с учетом интересов и прав местного населения, проживающего в границах ООПТ. Новым вызовом, по мнению авторов, является «разрыв» между ценностью и достоверностью региональных экотуристских инициатив в духе соответствия видовым характеристикам и принципам экологического туризма.

В целом, результаты исследования свидетельствуют о том, что процесс вовлечения российских ООПТ в развитие экологического туризма не является одномоментным и требует системного подхода к созданию ТРК в увязке с развитием ООПТ и прилегающих территорий. Поэтому подобная конкурсная практика может служить эффективным инструментом стимулирования субъектов РФ по созданию условий для организации и развития экологического туризма на ООПТ федерального, регионального и местного значения.

Исследование выполнено при финансовой поддержке гранта РФФИ в рамках научного проекта №20-01000665. 


\section{Список литературы}

1. Афанасьева А. В. Зарубежный опыт управления в сфере экологического туризма: тренды и модели развития // Сервис в России и за рубежом. 2020. Т.14. № 3 (90). С.27-56.

2. Максанова Л. Б.-Ж., Гусева Е. Ю., Оюнгэрэл Б., Аюшеева С. Н., Мункуева В. Д. Международный опыт развития экотуризма: страновая специфика и общие подходы // Вестник Московского государственного областного университета. Серия: Естественные науки. 2019. № 2. С. 54-66.

3. Международный опыт развития экологического туризма на особо охраняемых природных территориях. 2019. 258 с. [Электронный pecypc]. URL: https://asi.ru/library/ecotourism/116263.

4. Khanra S., Dhir A., Kaur P., Mäntymäki M. Bibliometric analysis and literature review of ecotourism: Toward sustainable development. Tourism Management Perspectives. 2021, Vol. 37, 100777. DOI: .https://doi.org/ 10.1016/j.tmp.2020.100777.

5. Songjun Xu, Liang Mingzhu, Naipeng Bu, Steve Pan Regulatory frameworks for ecotourism: An application of Total Relationship Flow Management Theorems. Tourism Management. 2017, Vol. 61, pp. 321-330.

6. Dzhandzhugazova E. A., Maksanova L. B.-Zh., Bardakhanova T. B., Ponomareva I. Yu., Blinova E. A. Ecotourism Development in Russia: Analysis of Best Regional Practices // Ekoloji. 2019, Vol. 28, № 107. pp. 411-415.

7. Голубчиков Ю. Н., Кружалин К. В., Хлынов А. Ю., Хлынова Н. В. Экотуризм на заповедных территориях // Вестник Национальной академии туризма. 2014. № 2 (30). С. 19-22.

8. Карпова Г. А., Ткачев В. А. Перспективные направления развития экологического туризма в России // Вестник Национальной академии туризма. 2019. № 2 (50). С. 15-16.

9. https://priroda.life 